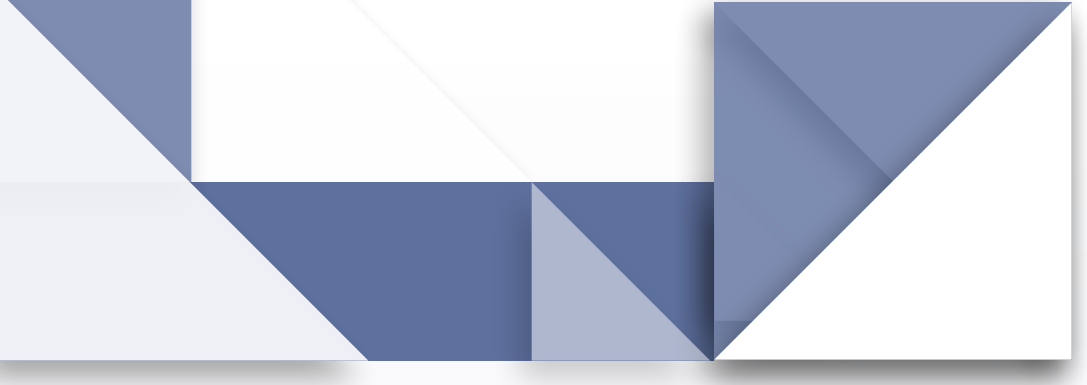

\title{
1) A associação entre o ensino de ciências e as moedas brasileiras
}

\section{- An Association between the Science Teaching and Brazilian Coins}

\section{- La asociación entre la enseñanza de ciencias y las monedas brasileñas}

\section{Resumo}

Sugerimos com este artigo de pesquisa uma forma diferenciada de se trabalhar o ensino de ciências. Com uma possível aproximação entre a arte, a cultura e a ciência, torna-se possível promover um maior interesse dos estudantes em relação ao ensino de ciências. Objetivamos investigar quais moedas possuem potencial para ser utilizadas no ensino de ciências. Assim, foi realizada uma pesquisa investigativa na homepage brasileira: http://www.moedasdobrasil. com.br/moedas/index.asp, e selecionado um total de 29 moedas diferentes, com grande potencial para utilização no ensino de ciências. Com essas moedas os professores podem discutir variados conteúdos com seus alunos, como por exemplo, aspectos zoológicos e religiosos das aves, o conteúdo de botânica interligado com a história do Brasil, a importância da educação alimentar saudável, os prejuízos causados pelo uso de agrotóxicos no meio ambiente, aspectos relacionados à zoologia dos peixes, o conteúdo Terra e Universo, dentre outros, como animais da fauna brasileira em risco de extinção. Como as moedas carregam em si a história do Brasil, percebemos também uma oportunidade de promover a interdisciplinaridade e transversalidade entre os conteúdos das disciplinas de história e ciências, contribuindo para que os diferentes saberes sejam trabalhados em conjunto.

Palavras-chave

ensino de ciências; moedas brasileiras; ciência e arte; estratégias didáticas

\section{Abstract}

We suggest with this study a differentiated way of working science teaching. With a possible approximation between art, culture and science, it becomes possible to promote a greater interest of students in science teaching. We aim to investigate which coins have the potential to be used in science teaching. Thus, investigative research was carried out in the Brazilian homepage: http:// www.moedasdobrasil.com. br/moedas/index.asp and a total of 29 different coins were selected, whose potential for use in science teaching is great. With these coins, teachers can discuss numerous contents with their students, such as the zoological and religious aspects of birds, the content of botany interconnected with Brazil's history, the importance of healthy food education, the damages

\section{Izabella de Freitas Acipreste* Lucas de Esquivel Dias Brandão** Danielle Ornelas Amorim*** Marcelo Diniz Monteiro de Barros ${ }^{* \star *}$}

Mestre em Biologia de Vertebrados pela Pontifícia Universidade Católica de Minas Gerais (PUC Minas). Bacharel em Ciências Biológicas pela puc Minas, Belo Horizonte, Minas Gerais, Brasil. Correio eletrônico: belafreitas95@gmail.com Orcid: https://orcid.org/0000-0002-6326-9811

** Mestre em Biologia de Vertebrados pela puc Minas. Bacharel e Licenciado em Ciências Biológicas pela PUc Minas. Professor de ciências na Escola Estadual Nila Faraj, Vespasiano (MG), Brasil. Correio eletrônico: lucasdesquivel@hotmail.com Orcid: https://orcid.org/0000-0003-2777-9440

*** Mestre em Educação pela Puc Minas; Bacharel e Licenciada em Ciências Biológicas pela puc Minas. Correio eletrônico: domelasamorim@yahoo.com.br Orcid: https://orcid.org/0000-0001-8215-4529

**** Professor Adjunto IV do Departamento de Ciências Biológicas da PUC Minas. Professor do Programa de Pós-Graduação em Ensino em Biociências e Saúde pelo Instituto Oswaldo Cruz - Fiocruz, Rio de Janeiro, Brasil; Professor nível Iv, Grau A, da Faculdade de Educação da Universidade do Estado de Minas Gerais (UEMG), Belo Horizonte, Minas Gerais, Brasil; Professor do Programa de Pós-Graduação em Educação: Educação e Formação Humana da UEMG. Correio eletrônico: marcelodiniz@pucminas.br Orcid: https://orcid.org/0000-0003-4420-5406 
caused by the use of pesticides in the environment, aspects related to the zoology of fishes, the content of Earth and Universe, among others, as endangered animals of the Brazilian fauna. As coins carry the history of Brazil, we also perceive an opportunity to promote interdisciplinarity and transversality between the contents of history and science disciplines, contributing so that the different pieces of knowledge are studied jointly.

Keywords

science teaching; brazilian coins; science and art; didactic strategies

\section{Resumen}

Sugerimos con este artículo de investigación una forma diferenciada de trabajar la enseñanza de ciencias. Con una posible aproximación entre el arte, la cultura y la ciencia, es posible promover un mayor interés de los estudiantes en relación con la enseñanza de ciencias. Nuestro objetivo es investigar cuáles monedas tienen el potencial de ser utilizadas en la educación científica. Así, se realizó una investigación en la página brasileña: http://www.moedasdobrasil.com.br/moedas/ index.asp, y fue seleccionado un total de 29 monedas diferentes, cuyo potencial para utilización en la enseñanza de ciencias es grande. Con estas monedas los profesores pueden discutir variados contenidos con sus alumnos, como por ejemplo, aspectos zoológicos y religiosos de las aves, el contenido de botánica interconectado con la historia de Brasil, la importancia de la educación alimentaria saludable, los daños causados por el uso de agrotóxicos en el medio ambiente, aspectos relacionados con la zoología de los peces, el contenido Tierra y Universo, entre otros, como animales de la fauna brasileña que están en peligro de extinción. Ya que las monedas cargan en sí la historia de Brasil, percibimos también una oportunidad de promover la interdisciplinariedad y transversalidad entre los contenidos de las disciplinas de historia y ciencias, contribuyendo para que los diferentes saberes sean trabajados en conjunto.

Palabras clave

enseñanza de ciencias; monedas brasileñas; ciencia y arte; estrategias didácticas 


\section{Introdução}

\section{Estratégias didáticas inovadoras no ensino de ciências naturais}

Atualmente, há várias opções que os professores de ciências dispõem para ensinar os seus conteúdos, e, nesse sentido, alguns autores têm proposto abordagens inovadoras para os docentes realizarem em suas práticas educativas. Por exemplo, através dos escudos e mascotes dos times brasileiros de futebol, o professor consegue trabalhar todos os grupos biológicos, como plantas (Brandão et al., 2017), peixes (Brandão e Barros, 2018), anfíbios e répteis (Brandão e Barros, 2017), aves (Dias et al., 2016) e mamíferos (Brandão et al., 2016). Uma vez que os times exibem essa fauna e flora em seus escudos ou mascotes. Outros esportes, como o basquetebol (Dumas, 2018), podem ser empregados para lecionar conteúdos da biologia, como por exemplo, a zoologia, uma vez que diversas equipes exibem, nos escudos de seus times, animais.

Uma interessante abordagem é a utilização de músicas no ensino. As letras da música popular brasileira permitem a discussão de variados temas (Barros et al., 2015). Como exemplo, dentro da biologia, os professores podem ensinar zoologia através das canções "Tico tico no fubá", de Zequinha de Abreu (Brandão et al., 2016), e "Aqui no Mar" (Brandão e Barros, 2016), interpretada por Diogo Nogueira. Da mesma maneira, é possível discutir botânica com os alunos através da canção "Tanto Mar" (Belisário et al., 2013), de Chico Buarque, pela canção "Feira de Magaio" (Brandão et al., 2014), de Sivuca e Glorinha Gadelha, ou até mesmo por meio da música "Espatódea" (Brandão et al., 2015), composta por Nando Reis. É possível também, pedir aos alunos que criem paródias de músicas, para que se possam fixar ainda mais os conhecimentos científicos (Rodeset al., 2019).

O professor pode aproximar o cinema do ensino, a partir da utilização de filmes, para discutir uma série de assuntos. Autores já publicaram Guias do Educador para se trabalhar, em sala de aula, os conteúdos presentes nos filmes: "Rango" (Pereira e Barros, 2017), "Procurando Dory" (Brandão et al., 2017) e "Uma prova de amor" (Melo e Barros, 2019).

Até mesmo as cédulas brasileiras, que apresentam aspectos importantes da sociedade, podem facilmente ser discutidos em sala de aula com os estudantes (Brandão et al., 2017). Figuras importantes no campo da ciência já foram representadas no dinheiro brasileiro através das cédulas, como Oswaldo Cruz, Carlos Chagas, Augusto Ruschi e Vital Brasil. Inspirado por essas possibilidades, o presente estudo, buscou aproximar o ensino de ciências das moedas brasileiras, pois até o momento, não se detectou trabalhos que relacionam as moedas brasileiras com a educação/ensino. Além disso, uma das linhas de pesquisa que os autores desse estudo trabalham, busca demonstrar as potencialidades da divulgação da flora e fauna brasileira por meio do dinheiro brasileiro (Brandão et al., 2017). Espera-se que as discussões aqui instigadas sejam utilizadas por professores no Ensino Fundamental e Médio em seus mais variados contextos. Mas, antes disso, faz-se necessário um breve histórico sobre as moedas brasileiras.

\section{Breve histórico das moedas brasileiras}

No Brasil, as primeiras moedas foram trazidas pelos portugueses, invasores e piratas. A partir de 1580, com a união das coroas de Portugal e Espanha, moedas de prata espanholas passaram a circular no Brasil em grande quantidade (Casa da Moeda do Brasil [CмB], 2015), 
porém somente durante o domínio holandês no nordeste brasileiro (1630-1654), surgiram as primeiras moedas cunhadas no Brasil: os florins e os soldos (Banco Central do Brasil [BCB], 2004).

Em 1694, D. Pedro II, rei de Portugal, criou a primeira Casa da Moeda, na Bahia. Todas as moedas de ouro e de prata em circulação na Colônia deveriam ser enviadas à Casa da Moeda para serem transformadas em moedas provinciais (BCB, 2004). A Casa da Moeda do Brasil é uma das mais antigas instituições públicas do Brasil e suas atividades se dedicaram originariamente, a recunhar as moedas portuguesas e espanholas em circulação (CMB, 2015).

Com o fim do Império e início do período republicano, ocorreram grandes mudanças no sistema monetário o que marcou profundas mudanças no meio circulante. O papel-moeda se popularizou e o Governo Federal se tornou o único emissor do dinheiro brasileiro, sendo que em 1942, o cruzeiro substituiu os réis (BCB, 2016).

A desvalorização do Cruzeiro levou à criação de um padrão de caráter temporário: o Cruzeiro Novo, em que Mil cruzeiros correspondiam a um cruzeiro novo (BCB, 2004).

De acordo com о вСв (2004), depois desse período de desvalorização, о padrão monetário brasileiro sofreu diversas modificações: em 1970, voltou a se chamar Cruzeiro, mas o crescimento da inflação a partir de 1980 foi a causa da instituição de um novo padrão monetário, o Cruzado. Em 1989, foi instituído o Cruzado Novo, com unidade equivalente a mil cruzados; em 1990, a moeda nacional voltou a se chamar Cruzeiro, com unidade equivalente a um cruzado novo; em 1993, uma nova reforma monetária foi promovida no país, instituindo o Cruzeiro Real, sendo que a unidade equivalia a mil cruzeiros; e em $1^{\circ}$ de julho de 1994, foi instituído o Real. Em 1998, foi cunhada uma nova família de moedas utilizando-se metais e tamanhos diferentes entre si, para facilitar o manuseio por parte da população (BCB, 2016).

Em 2010 foram lançadas novas cédulas de real, as quais têm tecnologia de segurança avançada: com tamanhos diferenciados e detalhes em alto relevo. O Banco Central afirma que as novas notas atendem às necessidades dos deficientes visuais, que têm dificuldade em reconhecer o valor das cédulas anteriores (Faber, 2016).

Diante desse histórico do sistema monetário brasileiro, percebeu-se que as moedas seriam um importante material didático para o ensino de ciências, por apresentarem temas relacionados à ciência. Além disso, há grande potencial para promover a interdisciplinaridade, ao envolver outras ciências, como matemática e história. 
Por influência do trabalho de Brandão et al. (2017), que associaram as cédulas brasileiras ao ensino de ciências e biologia, objetivamos, neste estudo, investigar quais moedas brasileiras possuem potencial para utilização no ensino de ciências. Assim, esperamos proporcionar o desenvolvimento da criticidade e da reflexividade do aluno, além de deixar claro a fertilidade existente quando associamos as moedas ao ensino das ciências, e que essa associação seja um elemento motivador na aprendizagem dos estudantes.

\section{Metodologia}

Foi realizada uma pesquisa investigativa na homepage http://www.moedasdobrasil.com. $\mathrm{br} /$ moedas/index.asp, que possui um completo compêndio das moedas brasileiras de todas as épocas. Desse site, foram retiradas todas as moedas que possuíam potencial para serem utilizadas no ensino de ciências. $\bigcirc$ site supracitado foi escolhido para servir de referência no presente estudo, já que tem grande relevância para a área numismática e apresenta todas as moedas brasileiras que nos interessam.

A investigação no referido site configura-se como uma pesquisa qualitativa (Thiollent, 1984), visto que foi examinado um único endereço eletrônico como campo de investigação para análise dos materiais disponibilizados. A técnica de investigação utilizada é a análise de site (Gerhardt e Silveira, 2009).

A pesquisa focou nos seguintes períodos: 1870 - 1890 Carimbos Divinos; ano de 1901 - Data em algarismos romanos; 1924 a 1934 Reflexo da inflação; 1964 a 1985 Regime Militar; 1970 a 1979 Cruzeiros $1^{\circ}$ família; 1979 a 1984 Cruzeiros 2 família inox; 1990 a 1992
Cruzeiros -inox; 1992 a 1993 Cruzeiro - Fauna aquática - inox; 1992 - Edições comemorativas do Cruzeiro; 1993 a 1994 Cruzeiros reais -inox; 1994 a 1998 Real; 1994 a 1997, Comemorativas do Real - $1^{a}$. Família; 2000 a 2014 edições comemorativas do Real - $2^{\circ}$ família e 2014 a 2016 - Série Jogos Olímpicos 2016 - Prata. No total, foram selecionadas 29 moedas diferentes com grande potencial para utilização no ensino de ciências.

\section{Resultados e discussão}

presente estudo possui o viés qualitativo pois os pesquisadores produziram informações aprofundadas e ilustrativas (Gerhardt e Silveira, 2009) sobre moedas com potencial para o ensino de ciências. Além disso, atribuíram um caráter interativo ao propor que professores a utilizem em suas práticas educativas.

\section{0 - 1890 Carimbos Divinos}

O símbolo da ave cunhado no anverso da moeda de cobre da Fig. 1A pode ser usado para trabalhar este grupo zoológico e estudar a presença das aves na simbologia humana e seu significado enquanto símbolo religioso. Nesse momento pode-se sugerir, como estratégia para o ensino de aves, a discussão com o viés religioso, a respeito da importância dessas como símbolo religioso. Pode-se informar aos alunos, por exemplo, que o pavão é uma ave que representa $\circ$ nascimento, longevidade e amor em alguns templos hindus na Índia (Mello, 2017), e essa mesma ave no budismo representa a pureza (Mello, 2017). Seria pertinente sugerir aos alunos que pesquisem outras aves que também possuem importância religiosa. 

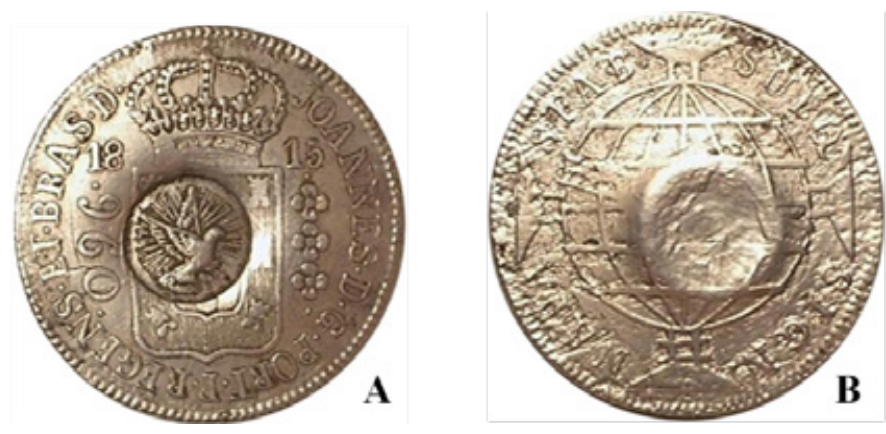

Figura 1. A e B: Moeda de 960 réis - A) Anverso. B) Reverso.

Fonte: elaboração própria.

As moedas das Figuras $2 \mathrm{~A}$ e 2B, 3A e 3B, 5A-D e 6A-F, trazem no anverso o café, o algodão, a soja, o feijão e a cana de açúcar.

\section{Data em algarismos romanos}

Essa moeda (Fig. 2A e 2B) foi cunhada durante o Brasil República (BCB, 2016).
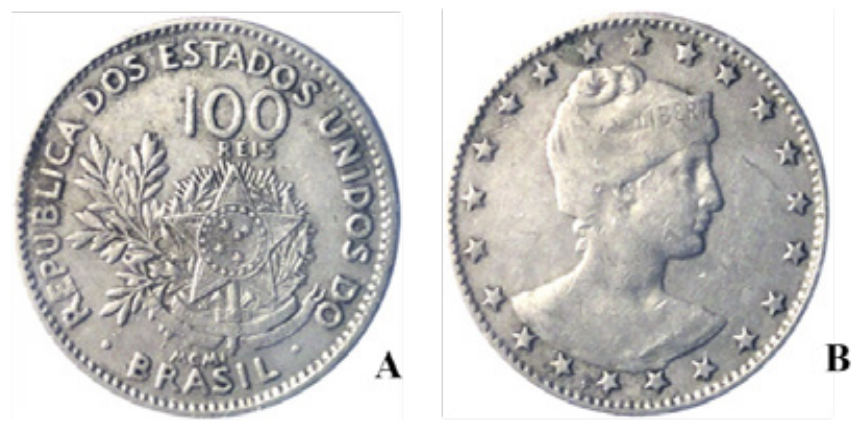

Figura 2. A e B: Moeda de 100 réis (mil réis) - A) Anverso: ramos de café. B) Reverso: Figura feminina representando a República e a liberdade.

Fonte: elaboração própria

Os professores podem aproveitar o café representado para informar aos alunos que a origem dessa planta se encontra no continente africano, e que o Brasil é um dos maiores produtores de café do mundo (Pereira, 2020). É possível também detalhar que a planta atinge entre 6 e 8 metros de altura e seu fruto apresenta duas sementes, que após serem processadas ficam conhecidas como o grão do café (Pereira, 2020). 


\section{4 - 1934 Reflexo da inflação}
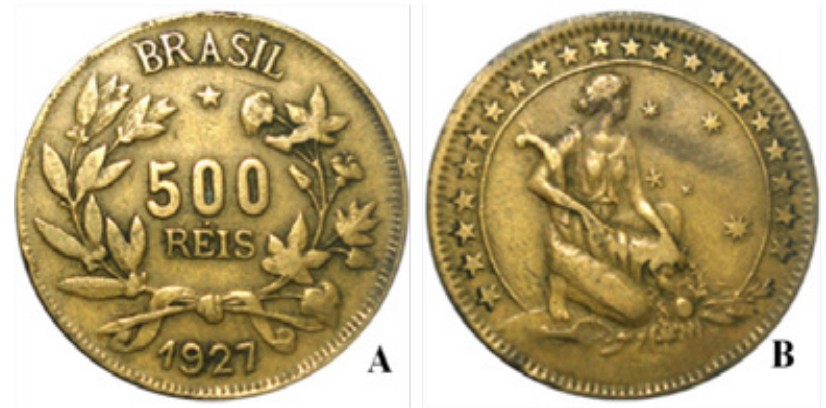

Figura 3. Moeda de 500 réis - A) Anverso: ramos de café e algodão. B) Reverso: a figura da abundância, com joelho apoiado em terra, tendo na destra uma cornucópia; no campo ao lado, a constelação do Cruzeiro do Sul. Em orla 21 estrelas.

Fonte: elaboração própria.

Pode-se aproveitar essa moeda para abordar a história do algodão. É interessante dizer que o algodão possui inúmeras espécies e as mais comuns originaram-se da África (Lerayer, 2010). No Paquistão, existem registros dessa planta que datam de 2700 anos .C, e no Peru as datações revelam espécies existentes entre 2500 a.C a 1750 a.C (Lerayer, 2010). Na China as datações revelam a origem no século VIII a.C (Lerayer, 2010).É interessante o professor destacar que, no Brasil, o melhoramento genético do algodão permitiu a redução da utilização de defensivos agrícolas, fato que proporcionou um cultivo mais saudável dessa planta no ambiente (Lerayer, 2010).

\section{4 - 1985: Regime Militar}

Com a moeda da Fig. 4A e 4B, poderão ser trabalhados os conteúdos relacionados ao grupo zoológico dos peixes, focando por exemplo, nas espécies ameaçadas de extinção no Brasil, como o dourado (Salminus franciscanus), é um peixe de importância econômica, tanto na pesca comercial quanto amadora e necessita realizar migrações reprodutivas durante as épocas de chuvas (Freitas et al., 2013). Nesse momento pode-se discutir também os efeitos que o barramento dos rios pode acarretar para a reprodução das espécies de peixes migradores. Pode-se citar também a pirapitinga (Brycon nattereri) como espécie de peixe ameaçada de extinção no Brasil e que possui o seu pico reprodutivo nos bimestres secos e de baixas temperaturas como abril/maio e junho/julho, não sendo portanto enquadrada no período de defeso da pesca brasileira, que ocorre nos meses de novembro a fevereiro (Brandão et al., 2020). 

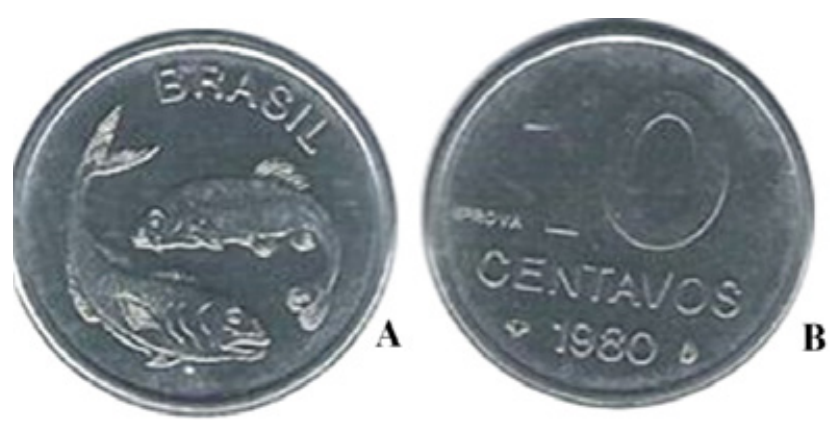

Figura 4. Moeda de 10 centavos - A) Anverso: peixes. B) Reverso.

Fonte: elaboração própria.

\section{0 - 1979 Cruzeiros $1^{\circ}$ família}
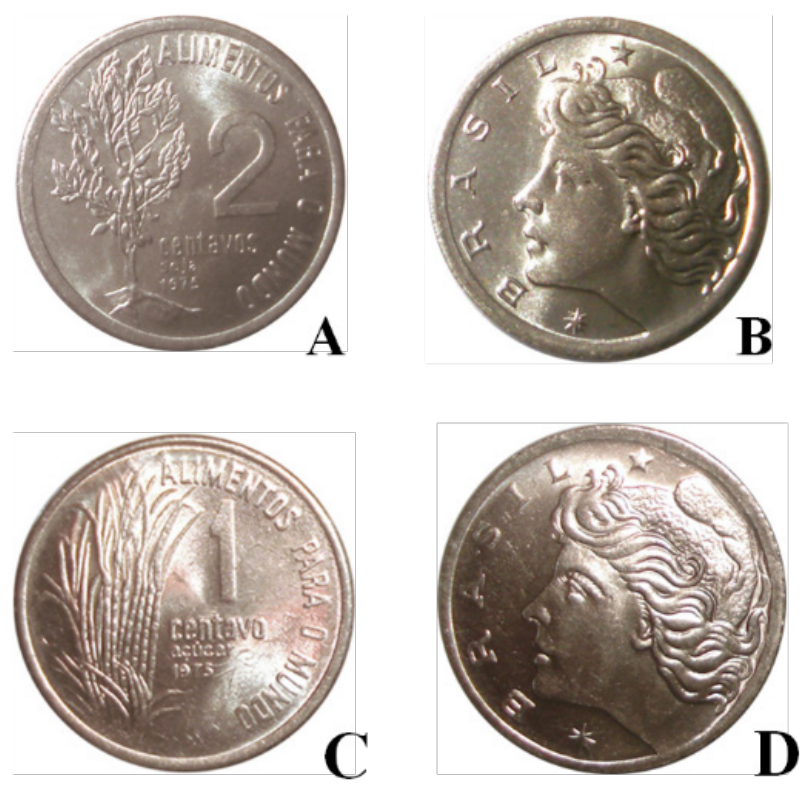

Figura 5. A e B. Moeda de 2 centavos - A) Anverso: Ramos de feijão e soja. B) Reverso. C e D: moeda de 1 centavo - C) Anverso: Cana-de-açúcar. D) Reverso.

Fonte: elaboração própria.

Os educadores podem se valer das moedas que apresentam o feijão e a soja para esclarecer, que nos nódulos das raízes dessas leguminosas existem bactérias responsáveis por realizar a fixação biológica do nitrogênio no solo (Uzunian e Birner, 2008). Portanto, as bactérias conseguem transformar o nitrogênio atmosférico em amônia, nitritos e nitratos, que são substâncias que os vegetais conseguem fixar no solo e enriquece-lo (Uzunian e Birner, 2008). Nesse novo solo, rico em compostos nitrogenados, as plantas poderão utilizar essas substâncias para a elaboração de seus compostos orgânicos e transmiti-los na teia alimentar para os níveis tróficos seguintes (Uzunian e Birner, 2008). 
Em relação às moedas que exibem a cana de açúcar, os professores podem mencionar a utilização de energias renováveis como o etanol. Nesse momento seria pertinente destacar que, do ponto de vista do rendimento, o etanol produzido a partir da cana de açúcar rende mais litros do que a produção de etanol a partir do milho, e que o plantio e posterior crescimento da cana de açúcar permite a absorção de parte do gás carbônico emitido pelos carros durante a queima desse biocombustível (Silveira, 2008).

\section{9 - 1984 Cruzeiros $2^{\circ}$ família inox}
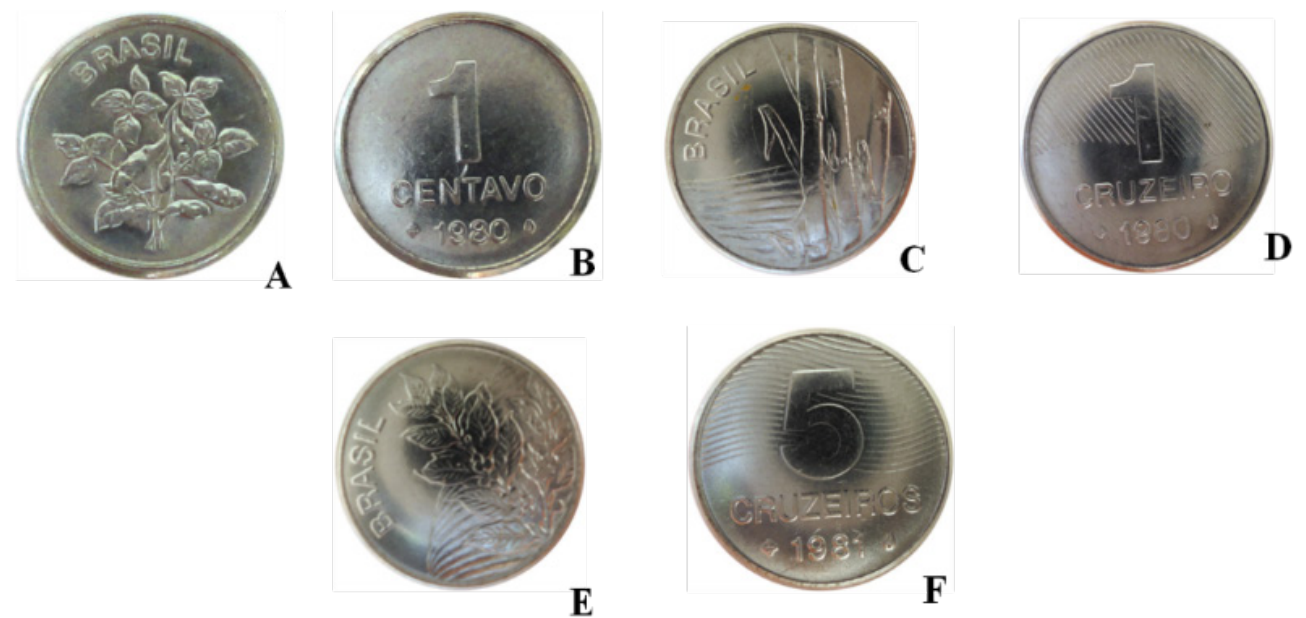

Figura 6. A e B: moeda de 1 centavo - A) Anverso: feijão-soja. B) Reverso. C e D: moeda de 1 cruzeiro.C) Anverso: cana-de-açúcar. D) Reverso. E e F: moeda de 5 cruzeiros - E) Anverso: ramos de café. F) Reverso. Fonte: elaboração própria.

\section{0 - 1992 Cruzeiros - inox}

Em 1990, uma nova reforma monetária modificou a unidade do sistema que voltou a se denominar cruzeiro. Na moedagem, foram cunhadas em 1990, nos valores de 50, 10, 5 e 1 cruzeiro, peças de aço inoxidável, tendo no reverso a representação de tipos humanos brasileiros, como a baiana, o seringueiro e o salineiro (Brasil, 2016).

Através dessas moedas, é possível, ainda, despertar o interesse de crianças, jovens e adultos, por englobar conceitos relacionados ao cotidiano como: o dia e a noite, as estações do ano e as fases da lua. No entanto, a Astronomia é pouco desenvolvida nos cursos de formação inicial de professores que lecionam nos anos iniciais do ensino fundamental (Bulegon e Coelho, 2013).

Nesta coleção, a moeda de interesse para o ensino de ciências pode ser a de 1 cruzeiro (Fig. 7A e 7B), com o Cruzeiro do sul no anverso. Pode ser introduzido o conteúdo Terra e Universo para o Terceiro ciclo, presente nos Parâmetros Curriculares Nacionais, trabalhando a constelação presente na América do Sul. Esse conteúdo amplia a orientação espaço temporal do aluno, a conscientização dos ritmos de vida e a elaboração de uma concepção do Universo, com especial enfoque no Sistema Terra-Sol-Lua (Brasil, 1998). 
De acordo com Gama e Henrique (2010), a Astronomia não é um mero acréscimo de conteúdo a ser tratado em sala de aula, mas oferece alternativas às formas de abordar mesmo outros temas e pode promover ricos debates sobre a história e a filosofia da ciência. No desenvolvimento desses estudos, é fundamental privilegiar atividades de observação e dar tempo para os alunos elaborarem suas próprias explicações (Brasil, 1998). Por último, o papel do professor, no caso do ensino de Astronomia, é o de possibilitar uma ponte entre as concepções íntimas do aluno e os conceitos que são aceitos pela comunidade científica (Aroca e Silva, 2011 1).

\section{2 - 1993 Cruzeiro - Fauna aquática - inox}

A partir de 1991, deixa de ser fabricada a moeda de 1 cruzeiro e, no ano seguinte, são lançadas as de 100 (Fig. 7C e 7D), 500 (Fig. 7E e 7F) e 1.000 (Fig. 7G e 7H) cruzeiros, sempre de aço inoxidável, retratando a fauna brasileira (Brasil, 2016).

Os professores podem informar aos alunos que as espécies de peixes de água doce consideradas ameaçadas de extinção incluem 5,9\% das conhecidas na fauna brasileira e que este número está subestimado, pois ainda falta conhecimento científico e taxonômico acerca das espécies. Com relação aos répteis, a fauna brasileira é muito rica e mais de um terço é endêmica (Brasil, 2010). Ainda de acordo com Brasil (2010), os mamíferos aquáticos estão em direta competição com o homem para conseguir recursos básicos como água, alimento e área de vida. As duas espécies de peixes-boi foram intensamente exploradas e mesmo protegidas por lei, ainda são alvo de intensa atividade antrópica.

Pode-se utilizar como estratégia de ensino abordar a situação dos animais da fauna brasileira que correm risco de extinção, além das principais ameaças e formas de conservação. Pode ser feito também um trabalho de caracterização da fauna brasileira levando-se em consideração o déficit de estudos que existe e um trabalho de educação ambiental em torno das espécies que estão ameaçadas.

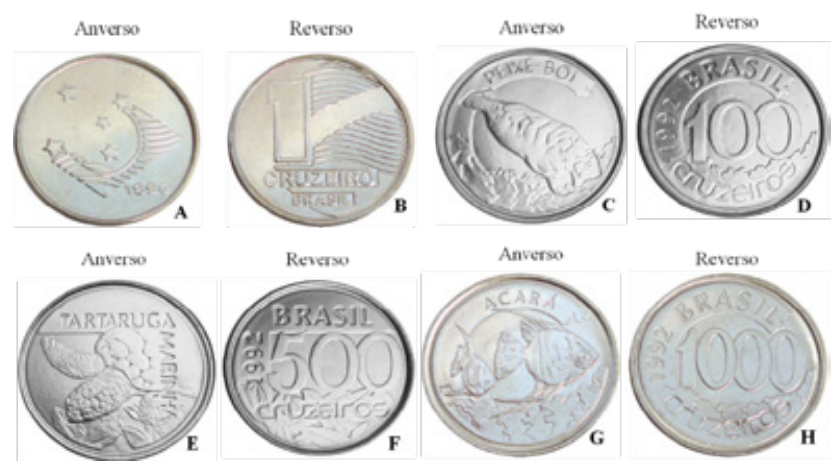

Figura 7. A e B: Moeda de 1 Cruzeiro- A) Anverso: Bandeira, Cruzeiro do Sul e data. B) Reverso. C e D: Moeda de 100 Cruzeiros - C) Anverso: figura do peixe-boi. D) Reverso. E e F: Moeda de 500 Cruzeiros - E) Anverso: figura da tartaruga marinha. F) Reverso. G e H: Moeda de 1000 Cruzeiros - G) Anverso: figura de dois peixes acarás. H) Reverso. 


\section{2 - Edições comemorativas do Cruzeiro}

Essa série é uma edição para colecionadores e não esteve disponível em circulação. Foi encontrada apenas uma moeda de interesse para o ensino de ciências, a de 2000 Cruzeiros, que mostra os Morros do Pão de Açúcar e da Urca no Rio de Janeiro em seu anverso, com a inscrição Meio Ambiente e Desenvolvimento (Fig. 8A e 8B).

Em 1992 realizou-se no Rio de Janeiro a Conferência da ONU sobre o Meio Ambiente e Desenvolvimento (Unced) com a participação de 170 países. Nessa conferência, reconhece-se a insustentabilidade do modelo de "desenvolvimento" então vigente. $\bigcirc$ desenvolvimento sustentável é visto como o novo modelo a ser buscado e nomeia-se a Agenda 21 como um Plano de Ação para a sustentabilidade humana (Dias, 2003).

Sugere-se aqui que pode ser feito um estudo sobre as principais conferências mundiais relacionadas ao meio ambiente, o que foi discutido em cada uma delas, seus resultados e consequências para a sociedade, para $\circ$ meio ambiente e para a educação ambiental.

\section{3 - 1994 Cruzeiros \\ reais - inox}

Em 1993, o governo Itamar Franco, a moeda é novamente desvalorizada em três decimais: - cruzeiro passa a chamar-se cruzeiro real. As poucas moedas do padrão cruzeiro real, cunhadas em aço inoxidável, acompanhavam a temática da fauna brasileira: as de 5 cruzeiros reais (Fig. 8C e 8D) traziam a figura da arara e as de 10 cruzeiros reais (Fig. 8E e 8F) a do tamanduá. Completando a série, surgiram em fins de 1993 as de 50 (Fig. $8 \mathrm{G}$ e 8H) e 100 (Fig. 9A e 9B) cruzeiros reais com os desenhos da onça-pintada e do lobo-guará, respectiva- mente, em substituição aos mesmos valores expressos em papel-moeda (Brasil, 2016).

Os professores podem mencionar para seus alunos que dentre os psitacídeos, as araras são as mais emblemáticas e sempre despertaram grande interesse pela capacidade de interação com as pessoas (Silva-Melo et al., 2019). Todavia, dentre os diversos problemas ambientais atuais relacionados as aves, pode-se destacar a degradação ambiental e o tráfico de animais que levam muitas espécies à ameaça de extinção (Presti et al., 2017).

Diante disso, torna-se pertinente ao professor mencionar e alertar os alunos sobre a ilegalidade do tráfico de animais e a importância do hábitat para a conservação das espécies. Dissertando sobre a capital do estado do Mato Grosso do Sul, Mamede e Benites (2018) apontam que a presença de Unidades de Conservação de Proteção Integral, numerosas áreas verdes e de fontes hídricas no município propiciam a ocorrência de alta riqueza de aves na matriz urbana.

Soma-se a isso, a atividade de observação de aves que é uma das possibilidades de lazer e entretenimento em meio à natureza mais antiga que se tem conhecimento, à qual se agregam vários benefícios, a exemplo bem-estar físico e emocional (Mamede e Benites, 2018). Nesse sentido, o conhecimento sobre a arara proporciona ao professor a oportunidade de promover um aprendizado além da sala de aula, devido a possibilidade de maior contato com a natureza para seus alunos, através da visitação de Unidades de Conservação e a possível observação desses animais.

De acordo com Chiarello et al. (2008) uma das ordens de Mamíferos que têm maior proporção de espécies ameaçadas é a carnívora. Isto porque seus indivíduos são predominantemente predadores, possuem grande 
necessidade de espaço e possuem baixa densidade populacional (Chiarello et al., 2008). Além disso, encontraram relatos de conflitos relacionados a presença de mamíferos em ambientes antropizados, sendo a predação dos animais domésticos o maior agravante desencadeador desses conflitos.

Em relação as moedas que exibem os mamíferos, o professor pode trabalhar com seus alunos a relação existente entre o ser humano e a natureza e o avanço das áreas urbanas sobre os habitats naturais. $\bigcirc$ professor pode mencionar, a exemplo, as rodovias: elementos que convertem os ambientes naturais em artificiais no processo de desenvolvimento da sociedade (Guimarães et al., 2018), ressaltando o fato de que os mamíferos são os animais atropelados com maior frequência (Deffaci et al., 2016).

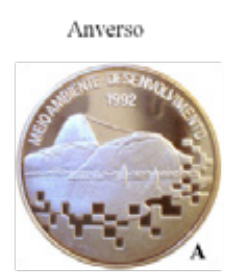

Anverso

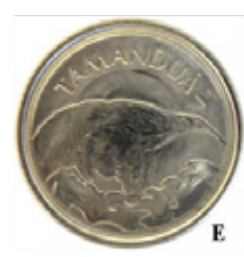

Reverso

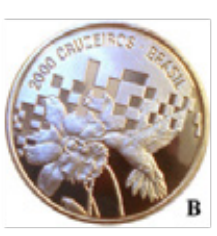

Reverso

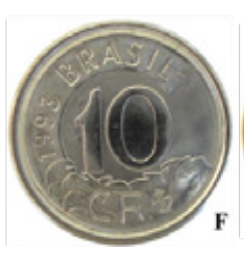

Anverso

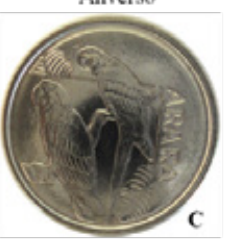

Anverso

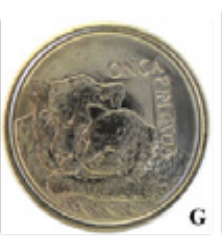

Reverso

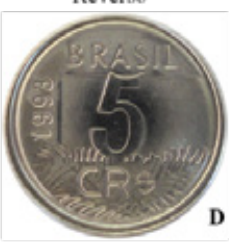

Reverso

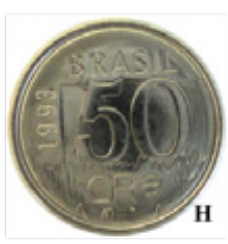

Figura 8. A e B: Moeda de 2000 Cruzeiros. A) Anverso: morros do Pão de Açúcar e da Urca, no Rio de Janeiro. B) Reverso: orquídea e beija-flor. C e D: Moeda de 5 Cruzeiros Reais. C) Anverso: duas araras. D) Reverso. E e F: Moeda de 10 Cruzeiros Reais. E) Anverso: tamanduá. F) Reverso. G e H: Moeda de 50 Cruzeiros Reais: G) Anverso: onça-pintada. H) Reverso.

Fonte: elaboração própria.

\section{4 - 1998 Real}

Em $1^{\circ}$ de julho de 1994 foi instituído o Real. Grande ênfase foi dada às moedas: surgiram na mesma data, nos valores de 1 real (Fig. 9C e 9D) e de 50, 10, 5 e 1 centavos, cunhadas em aço inoxidável, tendo numa das faces a efígie da República e no seu reverso a imagem de uma bromélia. Meses depois, dada à escassez de troco, tornou-se necessária a cunhagem de moedas de 25 centavos (Brasil, 2016).

As bromélias são plantas monocotiledôneas da família Bromeliacea e nativas das Américas. Sugere-se ao professor trabalhar as interações ecológicas entre 
plantas e animais. A exemplo, as bromélias são muito importantes para a manutenção de assembléias de sapos em planícies costeiras arenosas (Mageski et al., 2017).

\section{4 - 1997 Comemorativas do Real - $1^{a}$. Família}

Essa é uma edição comemorativa do centenário da cidade de Belo Horizonte. A moeda da figura $9 \mathrm{E}$ e $9 \mathrm{~F}$ foi feita apenas para colecionadores.

Atentar para a presença das aves no reverso (Fig. 9F) da moeda. As aves são, muitas vezes, utilizadas como símbolo de liberdade. Esse simbolismo pode representar as experiências e observações das pessoas sobre o ambiente, uma vez que o comportamento do animal é associado ao cotidiano (Ismail et al., 2017). $O$ professor pode trabalhar com seus alunos o papel cultural que estes animais possuem, procurando entender o significado cultural atribuído as aves pela sociedade.
2000 - 2014 edições comemorativas do Real - $2^{\circ}$ família

Essa edição comemorativa é referente ao centenário da imigração japonesa no Brasil. Trata-se de moeda feita apenas para colecionadores, representada na Figura $9 \mathrm{G}$ e 9H. Em seu reverso (Figura 9H), esta moeda apresenta uma agricultora japonesa trabalhando na colheita do caqui.

O professor pode explicar aos seus alunos que o caquizeiro é uma planta tipicamente subtropical, com ampla capacidade de adaptação aos climas temperado e tropical (Lopes et al., 2014). O caqui é produzido tradicionalmente no Sudeste e Sul do Brasil, nos meses de fevereiro a junho (Lopes et al., 2014) e foi introduzido por imigrantes japoneses no início do século xx (Ferri et al., 2002). Diante desta bagagem cultural relacionada ao caqui, o professor pode abordar temas relacionados a origem dos alimentos, desde o cultivo até a compra nas feiras e supermercados.

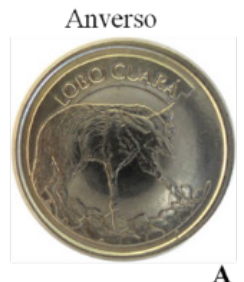

A
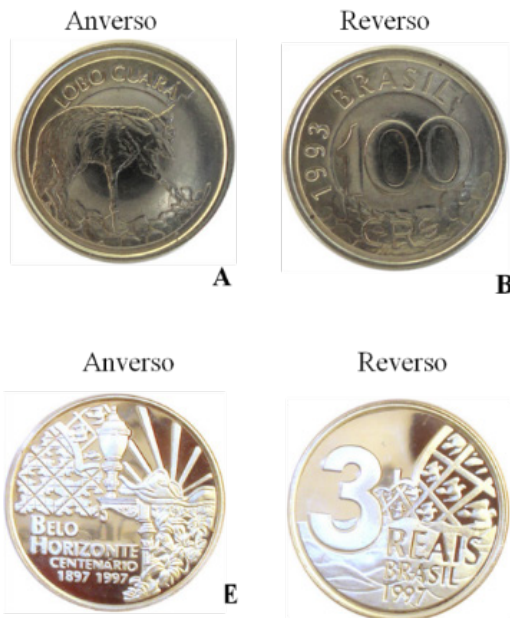

Reverso

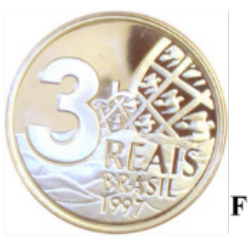

Anverso
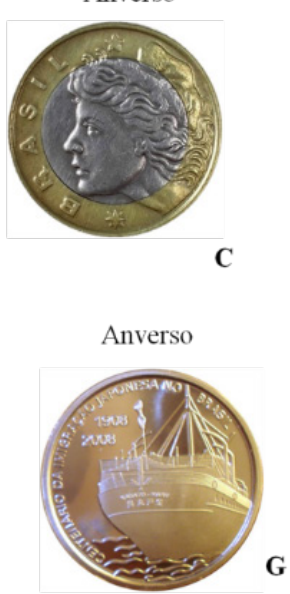

Reverso

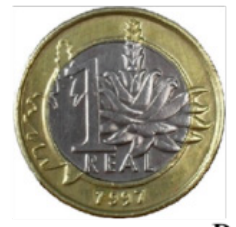

D

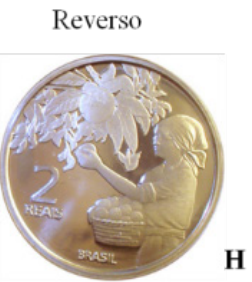

Figura 9. A e B: Moeda de 100 Cruzeiros. A) Anverso: figura de um lobo-guará. B) Reverso. C e D: Moeda de 1 Real (não circulada). C) Anverso. D) Reverso: a imagem de uma bromélia. E e F: Moeda de 3 Reais (Não circulada). E) Anverso: Igreja São Francisco, viaduto Sta Tereza e Serra do Curral. F) Reverso. G e H: Moeda de 2 reais. (Não circulada). G) Anverso: reprodução de foto do navio Kasato Maru. H) Reverso: representação de uma agricultora japonesa trabalhando na colheita do caqui. 


\section{4 - 2016 - Moedas da série Jogos Olímpicos 2016 - Prata}

As Figuras 10A-H e $11 \mathrm{~A}-\mathrm{H}$ apresentam as 8 moedas de prata comemorativas, referentes aos Jogos Olímpicos que ocorreram no Rio de Janeiro em 2016 . Essas moedas representam a série da fauna, lançadas em 28/1 1/2014. Todas não são circuladas e foram desenvolvidas para colecionadores.

A extensa costa e a vasta rede fluvial existentes no Brasil abrigam grande número de mamíferos aquáticos das ordens: Sirenia, Cetacea, Carnívora e os pinípedes. Esses mamíferos estão em direta competição com o homem em seus requerimentos básicos de sobrevivência, como alimento, água e área de vida (Chiarello et al. 2008). A toninha representada na figura 10B faz parte do grupo dos cetáceos e além desses problemas, este animal sofre com capturas incidentais ao longo da sua área de distribuição (Chiarello et al. 2008).

Um dos principais fatores de pressão a espécies terrestres são os relacionados às atividades agropecuárias que contribuem para a perda, fragmentação e diminuição da qualidade dos hábitats disponíveis para as espécies (ICMBio, 2018). Além disso, as pressões associadas a expansão da área urbana, caça, pesca, turismo desordenado, queimadas e mineração também são fatores relevantes para a perda de espécies (ICMBio, 2018).

Diante do exposto, torna-se relevante a conscientização das pessoas em relação aos impactos causados pela ação humana no planeta. Estes temas permitem a reflexão sobre hábitos de consumo, sobre a perda da biodiversidade e principalmente, em relação a sobrevivência da espécie humana em um planeta em crise. Sugere-se, portanto que o professor, possa trabalhar acerca da conscientização e reflexão dos alunos sobre hábitos, o papel e o impacto que cada um pode exercer no meio ambiente.

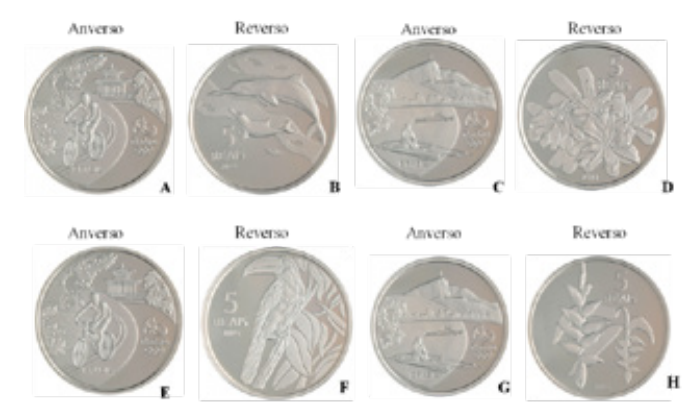

Figura 10. A e B: Moeda de 5 reais (não circulada). A) Anverso: atividade de ciclismo pelo Rio de Janeiro no Parque da Tijuca. B) Reverso: toninhas. C e D: Moeda de 5 reais (não circulada). C) Anverso: atividade de remo pelo Rio de Janeiro na Lagoa Rodrigo de Freitas com o Corcovado ao fundo. D) Reverso: conjunto de bromélias. E e F: Moeda de 5 reais (não circulada). E) Anverso: atividade de ciclismo pelo Rio de Janeiro no Parque da Tijuca. F) Reverso: tucano-de-bico-preto. G e H: Moeda de 5 reais (não circulada). G) Anverso: atividade de remo pelo Rio de Janeiro na Lagoa Rodrigo de Freitas com o Corcovado ao fundo. H) Reverso: botânica: exemplar de uma helicônia - planta ornamental originária da América do Sul. 

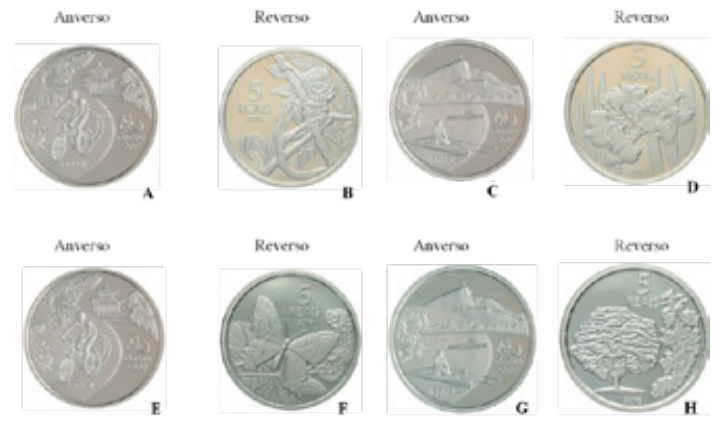

Figura 11. A e B: Moeda de 5 reais (não circulada). A) Anverso: atividade de ciclismo pelo Rio de Janeiro no Parque da Tijuca. B) Reverso: Mico Leão Dourado. C e D: Moeda de 5 reais (não circulada). C) Anverso: atividade de remo pelo Rio de Janeiro na Lagoa Rodrigo de Freitas. D) Reverso: orquídea. E e F) Moeda de 5 reais (não circulada). E) Anverso: atividade de ciclismo pelo Rio de Janeiro no Parque da Tijuca. F) Reverso: borboleta-da-praia. G e H: Moeda de 5 reais (não circulada). G) Anverso: atividade de remo pelo Rio de Janeiro na Lagoa Rodrigo de Freitas. H) Reverso: a árvore pau-brasil e, na lateral, destaque para um de seus ramos de folhas e flores.

Fonte: elaboração própria.

\section{Considerações finais}

Em seu modelo tradicional, o ensino de ciências tem favorecido a desmotivação dos alunos em sala de aula, entre outras razões, porque os professores concebem o conhecimento científico como verdade incontestável a ser transmitida independentemente das crenças, valores e conhecimentos prévios adquiridos pelos estudantes, que se veem obrigados a memorizar conceitos e a reproduzir os conteúdos ministrados em sala de aula (Porto et al., 2016).

Desta forma, sugerimos com este estudo uma forma diferenciada de se trabalhar o ensino de ciências. Com uma possível aproximação entre a arte, a cultura e a ciência, torna-se possível promover um maior interesse dos estudantes em relação as ciências. Assim, é notável que o professor de ciências possua um material amplo para trabalho, onde podem ser integrados temas e conteúdos que vão desde a zoologia até a botânica e a educação ambiental.

Como as moedas carregam em si a história do Brasil, percebemos também uma opor- tunidade de promover a interdisciplinaridade e transversalidade entre os conteúdos das disciplinas de história e ciências, contribuindo para que os diferentes saberes sejam trabalhados em conjunto. Espera-se que os professores de ciências tenham acesso a essa atividade e que possam, de acordo com seus anseios trabalhar os diferentes conteúdos que se fazem presentes nas moedas aqui selecionadas.

\section{Referências}

Aroca, S. C. e Silva, C. C. (2011). Ensino de Astronomia em um espaço não formal: observação do sol e de manchas solares. Revista Brasileira de Ensino de Física, 33, 1-1 1.

Banco Central do Brasil (BCB). (2016). Museu de valores: roteiro para guias de visitantes. Banco Central do Brasil. http://www.bcb. gov.br/htms/museu-espacos/GuiaMuseuModelo.pdf.

Banco Central do Brasil (BCB). (2004). Dinheiro no Brasil. https://www.bcb.gov.br/Pre/PEF/ PORT/publicacoes_DinheironoBrasil.pdf. 
Barros, M. D. M., Zanella, P. G. e Araújo-Jorge, T. C. (2015). Música no ensino de ciências: análise da presença de letras de músicas em livros didáticos de Ciências das séries finais do Ensino Fundamental no Brasil. European Review of Artistic Studies, 6, 1-17.

Belisário, R., Starling, M. F. V., Zanella, P. G. e Barros, M. D. M. (2013). Discutindo a revolução dos cravos nos contextos da Botânica e da História na educação básica, a partir da música 'Tanto Mar', de Chico Buarque (1978). Anais do Congresso Nacional de Botânica - Botânica Sempre Viva, Belo Horizonte, Minas Gerais, Brasil, 64․

Brandão, L. E. D., Andrade, J. G., Dias, D. V. C. e Barros, M. D. M. (2016). Ensinando zoologia a partir da letra da música 'Tico-tico no fubá', de Zequinha de Abreu. Revista Práxis, 8, 83 - 91.

Brandão, L. E. D., Amorim, D. O., Souza, M. M., Acipreste, I. F. e Barros, M. D. M. (2017). Ensinando Ciências e Biologia através das cédulas brasileiras. European Review of Artistic Studies, 8(2), 32-65.

Brandão, L. E. D., Arantes, F. P., Santos, J. E., Rizzo, E. e Bazzoli, N. (2020). Reproductive variables of Brycon nattereri Günther, 1864 (Pisces: Characidae), an endangered commercial species. Animal Reproduction Science. 213, 106272. https://doi.org/10.1016/i.anireprosci.2019.106272

Brandão, L. E. D. e Barros, M. D. M. (2018). O grupo dos peixes nos escudos dos times de futebol do Brasil. Revista Trilhas Pedagógicas, 8, 24-40.

Brandão, L. E. D. e Barros, M. D. M. (2017). O potencial do uso de mascotes como anfíbios e répteis associado ao ensino das ciências e biologia. ARETÉ: Revista Amazônica de Ensino de Ciências, 10, 61-73.

Brandão, L. E. D. e Barros, M. D. M. (2016). A utilização da música Aqui no mar como estratégia pedagógica para o ensino de Ciências e Biologia. European Review of Artistic Studies, 7, 1-20.

Brandão, L. E. D., Belisário, R., Rodrigues, H. T. S., Starling, M. F. V., Diniz, P. G. Z. e Barros, M. D. M. (2014). Ensinando Botânica a partir da música 'Feira de mangaio' de Sivuca e Glorinha Gadelha (1979). Anais do Congresso Nacional de Botânica. Salvador, Bahia, Brasil.

Brandão, L. E. D., Belisário, R., Rodrigues, H. T. S., Starling, M. F. V., Zanella, P. G. e Barros, M. D. M. (2015). A utilização da música 'Espatódea' como estratégia para o ensino de botânica: aproximações com o ensino de Ciências e Biologia. Anais do Congresso Nacional de Botânica, Santos, São Paulo, Brasil, 66 .

Brandão, L. E. D., Matta, R. R. e Barros, M. D. M. (2017). As potencialidades do filme Procurando Dory para o ensino de Ciências e Biologia. Interfaces da Educação, 8, 172-201. 
Brandão, L. E. D., Rodrigues, H. T. S. e Barros, M. D. M. (2017). As plantas representadas como mascotes dos times brasileiros de futebol. Ensino \& Pesquisa - Revista Multidisciplinar de Licenciatura e Formação Docente, 15, $21-45$.

Brandão, L. E. D., Rodrigues, H. T. S., Sousa, V. B. P. e Barros, M. D. M. (2016). Os mamíferos representados como mascotes dos times brasileiros de futebol. Revista Trilhas Pedagógicas, 6, 74-91.

Brasil, Moedas do. (2016). Catálogo das Moedas Brasileiras. Site de numismática. http:// www. moedasdobrasil.com. br/catalogo. asp? $s=88$.

Brasil, Ministério do Meio Ambiente. (2010). Livro Vermelho da Fauna Brasileira Ameaçada de Extinção. Brasília: Ministério do Meio Ambiente.

Brasil, Secretaria da Educação Fundamental. (1998). Parâmetros Curriculares Nacionais: Ciências Naturais. Brasília: Ministério da Educação.

Bulegon, A. M. e Coelho, F. B. O. (2013). Análise do tema Astronomia, nos livros didáticos indicados pelo PNLD, dos anos iniciais do ensino fundamental. VIDYA, 33(1), 1 17-128.

Casa da Moeda do Brasil (CMB). (2015). Catálogo comercial. Casa da Moeda. http:// www.casadamoeda.gov.br/portal/negocios/ catalogo-comercial.html

Chiarello, A. G., Aguiar, L. M. de S., Cerqueira, R., Melo, F. R., Rodrigues, F. H. G. e Silva, V. M. F. (2008). Mamíferos Ameaçados de Extinção no Brasil. In: Livro Vermelho da Fauna Brasileira Ameaçada de Extinção. 681-874.

Deffaci, A. C., da Silva, V. P., Hartmann, M. T. e Hartmann, P. A. (2016). Diversidade de aves, mamíferos e répteis atropelados em região de floresta subtropical no sul do Brasil. Ciência e Natura, 38, 1205-1216.

Dias, D. V. C., Brandão, L. E. D., Rodrigues, H. T. S., Sousa, V. B. P. e Barros, M. D. M. (2016). As aves como mascotes dos times brasileiros de futebol. Revista Trilhas Pedagógicas, 6, 9-26.

Dias, G. F.(2003). Educação Ambiental: Princípios e Práticas. Gaia.

Dumas, L. L. (2018). Air ball ou chuá? A Zoologia presente nos símbolos das equipes de basquetebol brasileiras e norte americanas. A Bruxa, 2(5), 1-31..

Faber, M. (2016). História do Dinheiro no Brasil. História Livre.

Ferri, V. C., Rinaldi, M. M., Luchetta, L. e Rombaldi, C. V. (2002). Qualidade de caquis Fuyu tratados com cálcio em pré-colheita e armazenados sob atmosfera modificada. Revista Brasileira de Fruticultura, 24, 385-388.

Freitas, L. J. A., Prado, P. S., Arantes, F. P., Santiago, K. B., Yoshimi, S., Bazzoli, N. e Rizzo, E. (2013). Reproductive biology of the characid dourado Salminus franciscanus from the São Francisco River, Brasil. Animal Reproduction Science, 139, 145-154.

Gama, L. D. e Henrique, A. B. (2010). Astronomia na sala de aula: por quê? Revista Latino-Americana de Educação em Astronomia, 9, 7-15.

Gerhardt, T. E. e Silveira, D. T. (2009). Métodos de pesquisa. Editora da Universidade Federal do Rio Grande do Sul.

Guimaraes, J. F., Silva, C. R. e Perin, M. A. A. (2018). Atropelamentos e influência da paisagem na sobrevivência de mamíferos silvestres de médio e grande porte. Revista Ibero Americana de Ciências Ambientais, 9, 54-70. 
ICMBio - Instituto Chico Mendes de Conservação da Biodiversidade. (2018). Livro vermelho da fauna brasileira ameaçada de extinção. ICMBio.

Ismail, W. N. W., Samian, A. L. e Muslim, N. (2017). Bird Element Symbolism in Malay Proverbs. InternationalJournal of Asian Social Science, 7, 119-125.

Lerayer, D. (2010). Guia do algodão: tecnologia no campo para uma indústria de qualidade. Cartilha do Conselho de Informações sobre Biotecnologia. 1-16. http://www.biologia.seed.pr.gov.br/arquivos/File/biotecnologia/algodao_biotecnologia.pdf.

Lopes, P. R. C., Oliveira, I. V. de M., Oliveira, J. E. de M. e Assis, J. S. (2014). Cultivo do Caquizeiro no Vale do São Francisco. Embrapa: circular técnica, 107, 1-9.

Mageski, M., Ferreira, R. B., Costa, L. C. D., Jesus, P. R. e Ferreira, P. D. (2017). Frog assemblage associated with bromeliads in a sandy coastal plain in the state of Espírito Santo, southeastern Brazil. Papéis Avulsos de Zoologia, 57, 445-449.

Mamede, S. e Benites, M. (2018). Por que Campo Grande é a capital Brasileira do Turismo de observação de aves e propostas para o fortalecimento da cultura local em relação a esta prática. Atualidades Ornitológicas, 23, 8-15.

Mello, A. (2017, 09 de junho). O simbolismo do pavão nas organizações religiosas. Publicado. http://ensinoreligiosoemsala.blogspot.com/2017/06/o-simbolismo-do-pavao-nas-organizacoes.html

Melo, D. R. e Barros, M. D. M. (2019). Guia do educador para o filme "Uma prova de amor". Praxis, 11, 65-78.

Pereira, F. P. (2020). A biologia do café. Publicado em 13/02/2020 no blog café de quinta. https://cafedequinta.com.br/a-biologia-do-cafe/.

Pereira, P. A. R. e Barros, M. D. M. (2017). Guia do educador para o filme Rango. Revista Pedagogia em Foco, 12, 205-222.

Porto, M. D., Santos, M. L. e Ferreira, J. R. R. (2016). Os desafios do ensino de Ciências no século XXI e a formação de professores para a educação básica. Goiás: Editora da Universidade Federal de Goiás.

Presti, F. T., Almeida, T. A., Silva, G. F., Silva, H. E., Conrado, L. P., Cespede, L., Magevski, T., Barbirato, M. e Pinto, A. (2017). Conhecendo a arara-azul-grande: confecção e aplicação de um jogo didático como parte das ações de Educação Ambiental visando a conservação da espécie. Revista Brasileira de Educação Ambiental (RevBeA), 12, 259-273.

Rodes, N. A., Mesquita, A. F. S. e Barros, M. D. M. (2019). A utilização das paródias 'Xote Chagásico' e 'Dengue, Zika e Chikungunya' como estratégias de educação em saúde no ensino de Ciências e Biologia. Experiências em Ensino de Ciências, $14,461-481$. 
Silva-Melo, M. R. D., Guedes, N. e Robaldo, M. (2019). Instituto Arara Azul: Integrando conservação, ciência cidadã e turismo Sustentável.Anais do $10^{\circ}$ Seminário de Iniciação Científica e $1^{\circ}$ Seminário de Pesquisa e Pós-Graduação Stricto Sensu. https://repositorio.pgsskroton.com/bitstream/123456789/24510/1/UNIDERP\%20 -\%20Marta\%20Regina\%20da\%20SilvaMelo.pdf.

Silveira, G. (2008, 05 de novembro). Como é produzido o etanol? Revista superinteressante. https://super.abril.com.br/ mundo-estranho/como-e-produzidoo-etanol/.
Thiollent, M. J. M. (1984). Aspectos qualitativos da metodologia de pesquisa com objetivos de descrição, avaliação e reconstrução. Cadernos de Pesquisa, 49, 45-50.

Uzunian, A. e Birner, E. (2008). Biologia. Harbra.

\section{Para citar esse artículo}

Acipreste, I. F., Brandão, L. E. D., Amorim, D. O., Barros, M. D. M., (2021). A associação entre o ensino de ciências e as moedas brasileiras. Tecné, Episteme y Didaxis: TED, (49), 143-162. https://doi.org/10.17227/ted. num49-10463 
